\title{
Champ littéraire fin de siècle autour de Zola, (Aa. Vv.) Béatrice Laville (textes réunis et présentés par)
}

\section{Bertrand Marquer}

\section{(2) OpenEdition}

1 Journals

\section{Édition électronique}

URL : http://journals.openedition.org/studifrancesi/35018

DOI : 10.4000/studifrancesi.35018

ISSN : 2421-5856

Éditeur

Rosenberg \& Sellier

\section{Édition imprimée}

Date de publication : 1 novembre 2005

Pagination : 439-440

ISSN : 0039-2944

\section{Référence électronique}

Bertrand Marquer, «Champ littéraire fin de siècle autour de Zola, (Aa. Vv.) Béatrice Laville (textes réunis et présentés par) », Studi Francesi [En ligne], 146 (XLIX | II) | 2005, mis en ligne le 30 novembre 2015, consulté le 18 avril 2021. URL : http://journals.openedition.org/studifrancesi/35018 ; DOI : https:// doi.org/10.4000/studifrancesi.35018

Ce document a été généré automatiquement le 18 avril 2021.

\section{(c)}

Studi Francesi è distribuita con Licenza Creative Commons Attribuzione - Non commerciale - Non opere derivate 4.0 Internazionale. 


\title{
Champ littéraire fin de siècle autour de Zola, (Aa. Vv.) Béatrice Laville (textes réunis et présentés par)
}

\author{
Bertrand Marquer
}

\section{RÉFÉRENCE}

Champ littéraire fin de siècle autour de Zola, (Aa. Vv.) Béatrice LAVILLE (textes réunis et présentés par), Modernités 20, Bordeaux, Presses Universitaires de Bordeaux, 2004, pp. 229

Les actes de ce colloque tenu à l'Université de Bordeaux III en décembre 2003 ne constituent pas une monographie mais visent à «effectuer en quelque sorte une coupe synchronique pour tenter de comprendre ce qui se joue, se tisse, se construit dans l'espace littéraire de la dernière décade du dix-neuvième siècle». Dans cette perspective, Émile Zola est avant tout envisagé comme le représentant d'une position emblématique sur l'échiquier littéraire, et ces actes tentent de le restituer au rapport dialectique et dynamique qu'il a entretenu avec le champ littéraire. Alain Pagès («Physiologie de l'assassin») revient tout d'abord sur le mystère entourant la mort de l'écrivain, et fait le point sur les indices réels dont dispose l'historien-enquêteur. Les trois articles suivants analysent les «marges» de l'œuvre zolienne: le drame lyrique (Henri Mitterand, «Zola et la scène lyrique: “L'Ouragan”»), peu étudié mais indispensable pour comprendre l'inspiration des Quatre Évangiles; le rapport entre texte et illustration dans l'édition du Rêve illustrée par le symboliste Carlos Schwabe (JeanPierre Leduc-Adine, «Roman, illustration/réception»), qui met en lumière à travers cet apparent choc esthétique la valeur duelle de ce roman «très psychologique» de Zola; les photographies zoliennes (Philippe Ortel, «Photographies zoliennes: vers un naturalisme élargi») qui mettent en scène l'appropriation croissante de l'appareil autorisée par les évolutions techniques, obligeant à resituer cette «instance biographique» dans le réseau d'idées et de représentations collectives et individuelles de cette fin de siècle. 
Puis Jean-Yves Mollier («Le paysage éditorial français au tournant du siècle») mesure les bouleversements du monde de l'édition et la représentation du "métier" de l'écrivain auxquels Zola a assisté, tandis que Francis Lacoste («De Zola à Loti: l'institution face au naturalisme») retrace les événements qui ont amené à faire de Pierre Loti le candidat en bien des points paradoxal et incontrôlable de l'institution, pour barrer à Zola le chemin de l'Académie Française, et que Jean-Michel Pottier («Militants, héritiers et novateurs; regards sur quelques romans à la mort de Zola») analyse la position des anciens du Manifeste des Cinq au moment de la mort de l'ancien maitre honni. Les cinq articles suivants portent sur les «liens complexes et privilégiés» qui ont uni Zola et d'autres écrivains: l'ancien disciple converti Huysmans (Jacques Noiray, «Huysmans critique de Zola et du naturalisme» et Gisèle Séginger, «Huysmans et Zola: les métamorphoses du roman»), l'ancien adversaire devenu fervent admirateur du dreyfusiste (Pierre Dufief, «Mirbeau face à Zola»), Anatole France utilisant à rebours de Zola l'utopie (Chantal Pierre-Gnassounou, «Bâtir en Utopie: Émile Zola/Anatole France»), l'ami toujours respectueux malgré les attaques esthétiques (Marie-Ange Voisin-Fougère, «Émile Zola et Paul Bourget: une rencontre littéraire»). Les trois derniers articles interrogent l'héritage immédiat et vite infidèle de Zola: l'acte fondateur du «J'accuse» dans l'archéologie de la pensée de Péguy (Béatrice Laville, «Le regard de Charles Péguy»), la référence ambiguë à Zola chez le Gide de Paludes, avant tout soucieux de faire porter la polémique contre le camp symboliste dont il est issu (Silvia Disegni, «Paludes de Gides: un récit-manifeste anti-zolien?»), et l'influence finalement stérilisante du Zola de Fécondité et du Docteur Pascal sur les écrivains naturistes au tournant du siècle (Jean-Louis Cabanès, «Les écrivains naturalistes et le modèle zolien»). 